21

\title{
Вынужденное низкочастотное комбинационное рассеяние света В монокристаллическом алмазе с заглубленным графитизированным слоем
}

\author{
(C) М.В. Тареева ${ }^{1}$, В.А. Дравин ${ }^{1}$, Р.А. Хмельницкий ${ }^{1}$, Н.В. Чернега $^{1}$, \\ А.Д. Кудрявцева ${ }^{1}$, М.А. Шевченко ${ }^{1}$, А.О. Литвинова ${ }^{1,2}$ \\ ${ }^{1}$ Физический институт им. П.Н. Лебедева РАН, \\ 119991 Москва, Россия \\ ${ }^{2}$ ВХНРЦ им. академика И.Э. Грабаря, \\ 105005 Москва, Россия \\ e-mail: tareeva@sci.lebedev.ru
}

Поступила в редакцию 10.10.2018 г.

В окончательной редакции 10.10.2018 г.

Принята к публикации 06.11.2018 г.

\begin{abstract}
Представлены результаты экспериментального наблюдения вынужденного низкочастотного комбинационного рассеяния света (ВНКР) в монокристаллическом алмазе с заглубленным графитизированным слоем, которое является результатом нелинейного взаимодействия мощного лазерного импульса наносекундной длительности с собственными колебаниями наноразмерных слоев алмазно-графитовых структур. Показано, что частотный сдвиг ВНКР составляет величину порядка $10 \mathrm{GHz}$ и обратно пропорционален геометрическим размерам нанослоев, составляющих структуру.
\end{abstract}

DOI: $10.21883 /$ OS.2019.03.47380.312-18

\section{Введение}

Одним из многочисленных оптических эффектов, наблюдаемых в наноразмерных системах, является низкочастотное комбинационное рассеяние света, впервые экспериментально зафиксированное в 1986 г. [1]. Индуцированный аналог этого процесса, а именно вынужденное низкочастотное комбинационное рассеяние (ВНКР) света, был впервые зафиксирован авторами настоящего исследования [2].

Физический механизм ВНКР аналогичен механизму вынужденного комбинационного рассеяния света (ВКР) на молекулярных колебаниях, при котором рассеяние происходит из-за флуктуаций дипольного момента, индуцированного в молекулах (в случае ВНКР - в наночастицах) полями возбуждающего и рассеянного излучений. При возбуждении среды мощным лазерным импульсом происходит когерентная раскачка колебаний наночастиц полями накачки и рассеяния; при этом рассеянная волна представляет собой волну спонтанного комбинационного рассеяния на тепловых флуктуациях размера и формы. Максимальная эффективность преобразования излучения накачки в акустическое возбуждение среды определяется соотношением частот падающего излучения и собственных колебаний и может достигать величины порядка $10^{-3}$.

ВНКР является так называемым q-независимым типом рассеяния, т.е. компоненты ВНКР могут распространяться как в направлении „вперед“, т.е. попутно с накачкой, так и в направлении „назад“, навстречу накачке. Это означает отсутствие зависимости величины частотного сдвига от угла между волновыми векторами возбуждающего и рассеянного света, в отличие от рассеяния света на акустических фононах в однородной среде (как, например, для рассеяния МандельштамаБриллюэна). Таким образом, меняя условия возбуждения, можно менять и эффективность преобразования ВНКР для рассеяния „вперед“ и „назад“.

В случае если возбуждаемая мода является комбинационно активной (как, например, для случая инверсионной симметрии), она проявляется в спектре ВНКР.

Теоретические оценки показывают, что частота генерируемого терагерцового излучения при когерентном возбуждении ансамбля наночастиц на частотах собственных акустических колебаний импульсным лазерным излучением должна быть обратно пропорциональна размеру наночастиц, т.е. частота ВНКР определяется морфологией возбуждаемых объектов и лежит в диапазоне от единиц гигагерц до терагерца в зависимости от типа исследуемых систем. Таким образом, варьирование размера наночастиц может стать инструментом направленного изменения частоты генерируемого излучения.

Эффективность преобразования волны накачки в волну рассеяния ВНКР в ансамблях некоторых типов наночастиц, в частности, диэлектрических фторидов редкоземельных элементов, достигает 20\% [3]. Порог возникновения эффекта оценивается как $0.01-0.05 \mathrm{GW} / \mathrm{cm}^{2}[2,4]$.

При этом, очевидно, должно также генерироваться непосредственно электромагнитное терагерцовое излучение, но к настоящему времени когерентное электромагнитное излучение терагерцового диапазона при 
возбуждении нелинейно-активных сред пока не наблюдалось.

В рамках настоящей работы представлены результаты экспериментального исследования вынужденного низкочастотного комбинационного рассеяния света в монокристаллическом алмазе с заглубленным графитизированным слоем, которое ранее не наблюдалось в алмазных структурах такого типа ни в вынужденном, ни в спонтанном режимах.

\section{Подготовка экспериментальных образцов}

В качестве активной среды для возбуждения нелинейного акустооптического взаимодействия были выбраны микронные монокристаллические алмазные пленки благодаря их выдающимся физико-химическим свойствам, отвечающим требованиям эксперимента, а именно: высокие значения модулей упругости алмаза, широкий комбинационный сдвиг однофотонной моды $\left(1332 \mathrm{~cm}^{-1}\right)$, относительно высокий показатель преломления среди оптически прозрачных сред и высокие коэффициенты теплопроводности. Экспериментальные образцы, представляющие собой пластинки монокристаллического алмаза (концентрация азота менее чем $5 \cdot 10^{18} \mathrm{~cm}^{-3}$ ), были вырезаны параллельно кристаллографической плоскости $\{110\}$ и в дальнейшем были подвергнуты ионной имплантации и отжигу [5] (рис. 1).

Полированные пластинки монокристаллического алмаза для данного эксперимента бомбардировались ионами углерода ${ }^{12} \mathrm{C}^{+}$, гелия ${ }^{4} \mathrm{He}^{+}$и дейтерия $\mathrm{D}^{+}$c энергиями $350,50 \mathrm{keV}, 350 \mathrm{keV}$ соответственно при комнатной температуре. Поскольку ионная имплантация приводит к радиационному повреждению, то последующий отжиг приводил к тому, что в области максимального радиационного воздействия образовывался графитизированный слой, в котором атомы углерода образуют связи по типу $s p^{2}[5,6]$. Отжиг осуществлялся в вакууме в течение часа при температуре $1480^{\circ} \mathrm{C}\left(1600^{\circ} \mathrm{C}\right.$ для образца $350 \mathrm{keV} \mathrm{D}^{+}$) при давлении $10^{-3} \mathrm{~Pa}$. Поверхностная графитизация стравливалась с помощью раствора $\mathrm{H}_{2}$ $\mathrm{SO}_{4}+\mathrm{K}_{2} \mathrm{Cr}_{2} \mathrm{O}_{7}$ при температуре около $180^{\circ} \mathrm{C}$.

В областях с уровнем радиационного повреждения ниже порога графитизации также создавались дефекты, но после отжига кристаллическая структура над заглубленным графитизированным слоем соответствовала высококачественному монокристаллическому алмазу.

Глубина залегания графитизированного слоя и толщина восстановленного монокристаллического алмазного слоя над ним определяются рядом параметров режима имплантации (тип и энергия ионов, доза имплантации) и могут контролироваться в процессе ионной имплантации. Это позволило получить образцы с различными размерами нанослоев алмазно-графитовой структуры. Положение графитизированного слоя и его толщина

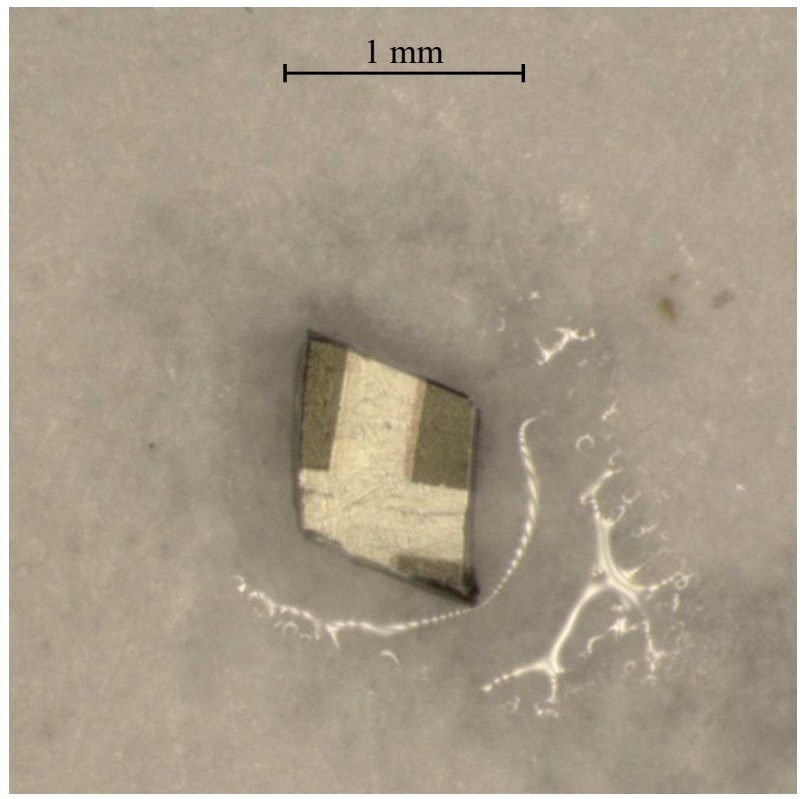

Рис. 1. Изображение монокристаллической алмазной пластинки с графитизированными слоями, полученными при имплантации ионов ${ }^{4} \mathrm{He}^{+}$с энергией $350 \mathrm{keV}$ (температура отжига образца $1480^{\circ} \mathrm{C}$ ), полученное с помощью цифровой камеры Axiocam ICc 5 оптического микроскопа Carl Zeiss. Затемненные области на образце (заглубленные графитизированные слои) соответствуют различным дозам имплантации ионов.

оценивались по распределению концентрации дефектов путем моделирования методом Монте-Карло [5].

\section{Экспериментальные результаты}

Вынужденное рассеяние в пленках возбуждалось импульсным излучением рубинового лазера (длина волны $\lambda=694.3 \mathrm{~nm}$; длительность импульса $\tau=20 \mathrm{~ns}$, спектральная ширина $\Delta v=0.015 \mathrm{~cm}^{-1}$, расходимость пучка $3.5 \cdot 10^{-4} \mathrm{rad}$, максимальная энергия в пучке $\left.E_{\max }=0.3 \mathrm{~J}\right)$, работающего в режиме модуляции добротности (рис. 2).

Излучение фокусировалось на поверхности образца под углами 30-60; плотность мощности в образце менялась в течение эксперимента с помощью набора линз с различными фокальными расстояниями и при изменении энергии возбуждающего излучения.

Высокоразрешающий интерферометр Фабри-Перо с переменной базой в диапазоне $0.4-16.67 \mathrm{~cm}^{-1}$ позволил провести измерения тонкой структуры спектра рассеяния. ВНКР проявилось в спектре рассеяния (на интерферограмме Фабри-Перо) в виде дополнительной (комбинационной) интенсивной линии рассеяния в стоксовой области. Ширина и интенсивность линии ВНКР были сравнимы с параметрами антистоксовых и стоксовых линий вынужденного комбинационного рассеяния (ВКР), ранее наблюдавшегося в образце монокристалла алмаза 


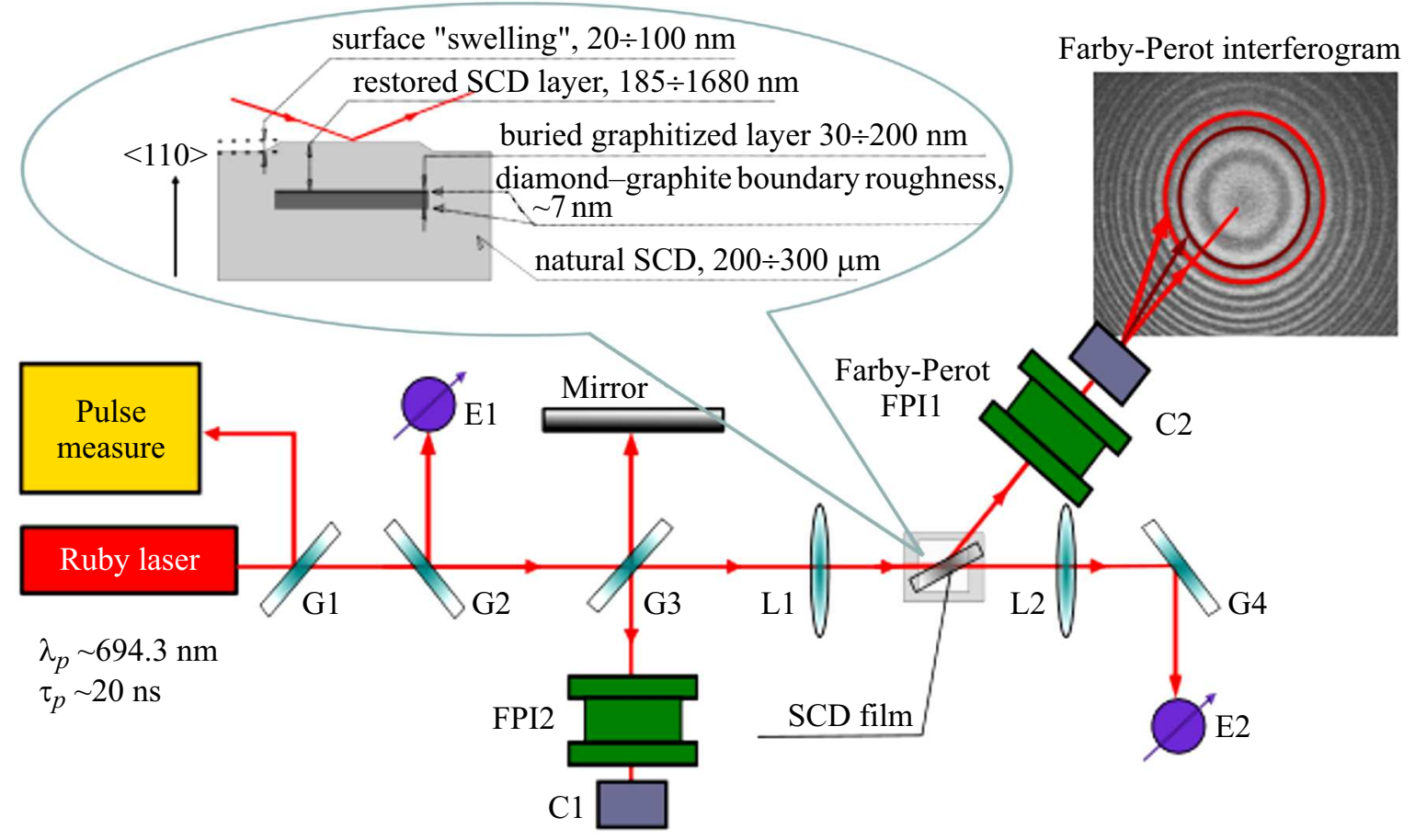

Рис. 2. Схема эксперимента. $G 1, G 2, G 3, G 4$ - стеклянные пластинки; $E 1, E 2$ - калиброванные фотодиоды для измерения энергии рассеянного света; Mirror - отражающее зеркало; FPI1, FPI2 - интерферометры Фабри-Перо для исследования рассеянного света; $C 1, C 2$ - фотодетекторы ; $L 1, L 2$ - линзы (фокальные расстояния $3-10 \mathrm{~cm}$ ), $S C D$ film - образец монокристаллической алмазной пленки с ионно-имплантированным графитизированным слоем, pulse measure - система измерения параметров возбуждающего излучения.

Таблица 1. Сравнительные характеристики субмикронных монокристаллических алмазных пленок с заглубленным графитизированным слоем, в которых наблюдалось ВНКР в гигагерцовом диапазоне частот

\begin{tabular}{c|c|c|c|c}
\hline $\begin{array}{c}\text { Энергия и тип ионов, } \\
\begin{array}{c}\text { бомбардировавших монокристалл } \\
\text { алмаза и сформировавших } \\
\text { графитизированный слой }\end{array}\end{array}$ & $\begin{array}{c}\text { Доза } \\
\text { имплантации } \\
\text { ионов, } \\
10^{16} \mathrm{~cm}^{-2}\end{array}$ & $\begin{array}{c}\text { Глубина залегания } \\
\text { графитизированного } \\
\text { слоя, nm }\end{array}$ & $\begin{array}{c}\text { Толщина } \\
\text { графитизированного } \\
\text { слоя, nm }\end{array}$ & $\begin{array}{c}\text { Частотный } \\
\text { сдвиг ВНКР, } \\
\mathrm{GHz}\end{array}$ \\
\hline $50 \mathrm{keV}^{4} \mathrm{He}^{+}$ & 2.5 & 185 & 84 & 9.3 \\
$350 \mathrm{keV}^{12} \mathrm{C}^{+}$ & 0.4 & 365 & 100 & 9 \\
$350 \mathrm{keV} \mathrm{D}{ }^{+}$ & 12 & 1680 & 150 & 8.4
\end{tabular}

с заглубленным графитизированным слоем, полученным путем ионной имплантации ионами гелия с энергией $180 \mathrm{keV}$.

Порог возбуждения эффекта составлял $0.01 \mathrm{GW} / \mathrm{cm}^{2}$. При этом максимальный коэффициент преобразования падающей энергии в ВНКР достигал значения $40 \%$.

Величина частотного смещения линии ВНКР от линии лазера составляла $0.3 \mathrm{~cm}^{-1}$ (а именно $0.31 \pm 0.01 \mathrm{~cm}^{-1}$ для образца $50 \mathrm{keV}{ }^{4} \mathrm{He}^{+}, 0.30 \pm 0.01 \mathrm{~cm}^{-1}$ для $350 \mathrm{keV}$ ${ }^{12} \mathrm{C}^{+}$и $0.28 \pm 0.01 \mathrm{~cm}^{-1}$ для $350 \mathrm{keV} \mathrm{D}{ }^{+}$) или 9.3, 9 и $8.4 \mathrm{GHz}$ (таблица 1). В таблице 2 для сравнения приведены также значения частот ВНКР, наблюдавшегося в объемных образцах синтетических опалов на основе диоксида кремния, представляющих собой трехмерные массивы плотноупакованных глобул $\mathrm{SiO}_{2}$ диаметром несколько сот нанометров. И для синтетических опалов, и для монокристаллических алмазов с заглубленным графитизированным слоем частотный сдвиг ВНКР обратно пропорционален геометрическим параметрам активной рассеивающей среды. Это связанно с тем, что мода собственных колебаний объекта в классическом приближении определяется его морфологией (формой и упругими свойствами) [7].

Значения низкочастотного комбинационного рассеяния порядка $10 \mathrm{GHz}$ характерны для наноструктур с размерами рассеивающих центров порядка сотен нанометров [2,3,8-10], так как величина ВНКР обратно пропорциональна диаметру (размеру) наночастиц, совершающих собственные колебания в направлении, вдоль 
Таблица 2. Сравнительные характеристики объемных матриц синтетических опалов, в которых наблюдалось ВНКР в гигагерцовом диапазоне частот

\begin{tabular}{c|c|c}
\hline $\begin{array}{c}\text { Спектральное } \\
\text { положение максимума } \\
\begin{array}{c}\text { в спектре } \\
\text { отражения, nm }\end{array}\end{array}$ & $\begin{array}{c}\text { Диаметр } \\
\text { глобул } \mathrm{SiO}_{2}, \\
\text { формирующих } \\
\text { матрицу опала, } \mathrm{nm}\end{array}$ & $\begin{array}{c}\text { Частотный } \\
\text { сдвиг } \mathrm{BHКР,} \\
\mathrm{GHz}\end{array}$ \\
\hline 601.2 & 270 & 7.8 \\
645.7 & 290 & 6.6 \\
696.1 & 315 & 5.1
\end{tabular}

которого в рассеивающем объекте (молекуле, вирусе, нанопленке) распространяется наблюдаемая мода ВНКР.

В наших экспериментах такая зависимость также обнаруживается: частоты ВНКР в монокристаллической алмазной пленке обратно пропорциональны размерам нанослоев - толщине графитизированного слоя внутри алмазной пленки и его глубине залегания, т.е. толщине восстановленного монокристаллического алмазного слоя над ним. Таким образом, впервые было показано, что явление ВНКР может наблюдаться не только в наночастицах различной природы, в том числе образующих твердотельную периодическую наноструктуру (как в случае с синтетическими опалами), но и в наноструктурированных пленках, где акустический резонанс возникает на собственных колебаниях наносистемы монокристаллический алмаз-графитизированный слой. Для количественного описания колебаний с частотами порядка $10 \mathrm{GHz}$ необходима теория, учитывающая скорости распространения звука в графитизированном слое и его параметры упругости, а также взаимодействие звука на границе раздела монокристалл алмазаграфитизированный слой.

\section{Заключение}

Экспериментально продемонстрирована принципиальная возможность нелинейного возбуждения наноразмерной алмазной структуры, приводящая к вынужденному рассеянию в гигагерцовом диапазоне частот. Показано, что результатом возбуждения монокристаллических алмазно-графитовых структур импульсным лазерным излучением является генерация интенсивного когерентного излучения со сдвигом частоты на величину порядка $10 \mathrm{GHz}$, которая является характерной для наноструктур порядка сотен нанометров. Величина сдвига вынужденного низкочастотного комбинационного рассеяния света определяется морфологией наночастиц, составляющих наноразмерную систему, а именно их частотами собственных колебаний. Таким образом, вынужденное низкочастотное комбинационное рассеяние света является нелинейно-оптическим эффектом, позволяющим получать не только интенсивное рассеяние света на стоксовой частоте, но и осуществлять эффективное когерентное акустическое возбуждение гигагерцового (а в перспективе и терагерцового) диапазона непосредственно оптически-активной наноразмерной среды.

Результаты данного исследования могут быть направлены на создание источника когерентного электромагнитного излучения терагерцового диапазона частот на основе подобных алмазных наносистем.

Для целого ряда сложных молекул, собственные частоты колебательных и вращательных переходов которых лежат в терагерцовом диапазоне частот, ВНКР может использоваться для спектроскопии веществ, содержащих такие молекулы.

Полученное излучение высокой эффективности может быть использовано в качестве бигармонической накачки для генерации электромагнитного излучения разностной частоты, лежащей в тера- и гигагерцовом диапазонах.

Работа была выполнена при поддержке гранта РФФИ № 16-32-60026 мол-а-дк.

\section{Список литературы}

[1] Duval E., Boukenter A., Champagnon B. // Phys. Rev. Lett. 1986. V. 56. P. 2052. doi 10.1103/PhysRevLett.56.2052

[2] Tcherniega N.V., Samoylovich M.I., Kudryavtseva A.D., Belyanin A.F., Pashchenko P.V., Dzbanovski N.N. // Opt. Lett. 2010. V. 35. P. 300. doi 10.1364/OL.35.000300

[3] Safronikhin A.V., Ehrlich H.V., Lisichkin G.V., Kudriavtseva A.D., Mironova T.V., Shevchenko M.A., Strokov M.A., Tcherniega N.V., Zemskov K.I. // J. Russ. Laser Res. 2018. V. 39. N 3. P. 294. doi 10.1007/s10946-018-9721-5

[4] Tareeva M.V., Dravin V.A., Khmelnitsky R.A., Kudryavtseva A.D., Strokov M.A., Shevchenko M.A., Tcherniega N.V., Tsarik K.A. // J. Russ. Laser Res. 2017. V. 38. N 6. P. 530. doi 10.1007/s10946-017-9676-y

[5] Khomich A.V., Khmelnitskiy R.A., Dravin V.A., Gippius A.A., Zavedeev E.V., Vlasov I.I. // Phys. Solid State. 2007. V. 49. N 9. P. 1661. doi 10.1134/S1063783407090107

[6] Nshingabigwi E.K, Derry T.E., Naidoo S.R., Neethling J.H., Olivier E.J., O'Connell J.H., Levitt C.M. // Diam. Rel. Mat. 2014. V. 49. N 1. doi 10.1016/j.diamond.2014.07.010

[7] Montagna M. // Phys. Rev. B. 2008. V. 77. P. 045418. doi 10.1103/PhysRevB.77.045418

[8] Tcherniega N.V., Zemskov K.I., Savranskii V.V., Kudryavtseva A.D., Olenin A.Y., Lisichkin G.V. // Opt. Lett. 2013 V. 38. N 6. P. 824. doi 10.1364/OL.38.000824

[9] Kudryavtseva A.D., Tcherniega N.V., Samoylovich M.I., Shevchuk A.S. // International J. Thermophysics. 2012. V. 33 N 10-11. P. 2194. doi 10.1007/s10765-012-1259-0

[10] Karpova O.V., Kudryavtseva A.D., Lednev V.N., Mironova T.V., Oshurko V.B., Pershin S.M., Petroval E.K., Tcherniega N.V., Zemskov K.I. // Laser Phys. Lett. 2016. V. 13. P. 085701. doi 10.1088/1612-2011/13/8/085701 